\title{
Одна назидательная пьеса Плавта
}

\section{IIIIIIIIIIIIIIIIIIIIIIIIIIIIIIIIIIIIIIIIIIIIIIIIIIIIIIIIIIIIIIIIIIIIIIIIIIIIIIIIIIIIIIIIIIIIIIIIIIIIIII}

Т.А. Бобровникова

Статья посвящена комедии Плавта «Пленники». Плавт, подобно другим римским комедиографам, никогда не выступал в роли учителя зрителей. Это совершенно не соответствовало традициям римского республиканского театра, который имел чисто развлекательный характер. Однако автор статьи доказывает, что разбираемая пьеса и по сюжету и по всем приемам уникальна в творчестве римского поэта. Сам Плавт выделяет эту комедию и утверждает, что она написана не для развлечения зрителей, как все остальные, а с целью улучшить их нравы, т.е. Плавт здесь единственный раз выступает в столь несвойственной римской сцене роли учителя.

Задачей нашей статьи как раз является выяснение вопроса о том, чему же хотел научить Плавт своих соотечественников. Мы приходим к выводу, что тема комедии - отношение к рабам. С самого начала поэт резко осуждает работорговлю. Пьеса поставлена была во время Второй Пунической войны или сразу после нее. Сотни римлян попали в плен и стали рабами на чужбине. Поэт обыгрывает этот момент, старается вызвать у зрителей жалость к рабам, напоминая о судьбе их друзей и родственников. Он настойчиво повторяет - сегодня вы свободны, а завтра можете стать рабами. Главный герой говорит: «Судьба лепит и мнет людей, как ей заблагорассудится. Меня, который был свободен, она сделала рабом, свергнув с высоты в бездну. Меня, привыкшего повелевать, она заставила исполнять чужие приказания. Правда, если бы я нашел такого господина, каким был некогда сам, я бы мог не страшиться жестокости и несправедливости... Некогда я был свободен, как твой сын. Так же, как и у него, у меня отняла свободу вражеская рука. Он служит у наших точно так же, как я служу у тебя. Но есть Бог, который видит и слышит все, что мы делаем. И он будет заботиться о твоем сыне в соответствии с тем, как ты обращаешься со мной. За добро он воздаст добром, но и за зло воздаст равной мерой. Ведь мой отец тоскует обо мне так же, как ты о своем сыне». Таким образом, само божество, согласно Плавту, следит за отношением хозяина к рабам и карает его за причиненное зло. Очень интересным моментом мы считаем то, что многие места из нашей комедии перекликаются с политическими выступлениями известного современника Плавта, Катона Старшего. Анализ этих мест приводит автора этих строк к выводу, что комедия Плавта имеет острополемическую направленность. Средствами искусства Плавт стремится разбить доводы знаменитого политика.

The article is devoted to Plautus' comedy "The Captives». Plautus, like other Roman comedy dramatists, never acted as a teacher to the audience. This completely did not correspond to the traditions of the Roman Republican Theater, which was purely entertaining. However, the author proves that, among Plautus' works, the play 
under consideration is unique both in terms of the plot and techniques. Plautus himself singles out this comedy and claims that it is not written for the entertainment of the audience, like all the rest, but with the aim of improving their morals, that is, Plautus only once appears in the role of the teacher, which is so uncharacteristic of the Roman scene.

The task of our article is to find out what Plautus wanted to teach his compatriots. We come to the conclusion that the subject of the comedy is attitude towards slaves. From the very beginning, the poet sharply condemns the slave trade. The play was staged during the Second Punic War or immediately after it. Hundreds of Romans were captured and turned into slaves in foreign lands. The poet plays on this moment, tries to arouse pity for the slaves in the audience, reminding of their friends and relatives' fate. He keeps repeating - today you are free, and tomorrow you can become slaves. The protagonist says, "Human fortune moulds and fashions just as she wills. Myself, who was a free man she has made a slave, from the very highest the very lowest. I, who was accustomed to command, now obey the mandates of another. And indeed, if I meet with a master just such as I proved the ruler in my own household, I shall not fear that he will rule me harshly or severely... As free a man was I till lately as your son. As much did a hostile hand deprive me of my liberty as him of his. As much is he a slave among my people, as I am now a slave here with yourself. There is undoubtedly a God, who both hears and sees the things which we do. Just as you shall treat me here, in the same degree will he have a care for him. To the well-deserving will he show favour, to the ill-deserving will he give a like return. As much as you lament your son, so much does my father lament me." Thus, the deity itself, according to Plautus, monitors the attitude of the master to the slaves and punishes him for the harm done. We believe that a very interesting point is that many of the places in this comedy closely echo with the political speeches of the famous Plautus' contemporary, Cato the Elder. An analysis of these places leads the author to the conclusion that Plautus' comedy is of agonistic character. With the help of the art, Plautus strives to demolish the arguments of the famous politician.

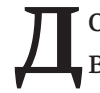

остаточно хорошо известно, какое разное место занимал театр в жизни древних Афин и республиканского Рима. В Афинах спектакль был настоящим священнодействием, находившимся под покровительством бога Диониса. Этого мало. Аристофан в «Лягушках» прямо определяет роль автора театральных пьес в афинском обществе: «...Малых ребяток / Наставляет учитель добру и пути, а людей возмужавших - поэты (1054-55)».

Таким образом, поэт мыслился как учитель взрослых. И Эсхил в этой же комедии прямо требует у своего преемника Еврипида отчета в нравственном состоянии Афин. Естественно, и автор, и актеры окружены были глубочайшим почетом. Люди считали за честь выступить на сцене.

${ }^{1}$ Перевод Адр. Пиотровского. 
Совершенно по-иному дело обстояло в Риме. Для римлян театр с самого начала был пустой забавой, развлечением, актеры - чем-то вроде канатных плясунов или скоморохов. Ни один уважающий себя человек не мог стать актером. Тот, кто выступал на сцене, автоматически терял гражданские права. Поэтому артистами были в основном рабы и отпущенники ${ }^{1}$. Авторы пьес тоже обычно были не римляне. Теренций бывший раб, Плавт - чужеземец, сам актер, одно время работавший на мельнице, где трудились только рабы-преступники (Gell. III, 3, 14). Характерный факт. В Афинах на склонах Акрополя находился великолепный театр Диониса. В Риме III-II вв. вообще не существовало театра. Актеры приезжали с юга и где попало разбивали импровизированные подмостки. Это было что-то вроде европейского балагана. Когда же во II в. до н.э. любители греческой культуры задумали построить каменный театр, то по настоянию строгих блюстителей старины он был разрушен «Как предмет бесполезный и пагубный для общественной нравственности» (Liv. Ep. XLVIII, cp. App. B.C., I, 28).

Содержание пьес вполне оправдывало отношение зрителей. У Аристофана действующие лица - граждане Афин, люди во всех отношениях почтенные, и обсуждают они насущные проблемы государства. Герои Плавта - моты, кутилы, распутники и рабы-обманщики. Действие часто развертывается на пороге публичного дома.

Вот почему не может идти даже речи о какой-нибудь назидательности комедий Плавта. Это веселый вихрь масок, который должен был вызвать только радостное веселие. Но есть у Плавта одна удивительная комедия, совсем не похожая на прочие. Это «Пленники». Сам автор выделяет ее из всех остальных. В прологе он объявляет зрителям: «Для вас будет очень полезно уделить внимание этой пьесе. Она написана необычно, совсем не так, как остальные. Здесь нет непристойных стихов, которые потом нельзя повторить. Здесь нет бесчестного сводника, злой куртизанки и хвастливого воина» (Plaut. Capt., 54-58). А в Эпилоге он снова настойчиво повторяет: «Зрители, наша пьеса написана для очищения нравов. Здесь нет ни любви, ни интриг, ни подкинутого ребенка, ни мошенничеств с деньгами, ни влюбленного юноши, который тайком от отца выкупает потаскушку». Как видим, Плавт кратко и с насмешливым презрением перечисляет сюжеты эллинистических комедий. Зачем же написана эта столь необычная комедия? Автор объясняет: «Поэты мало пишут таких пьес, чтобы хорошие люди стали еще лучше» (Ibid., 1033-1034).

\footnotetext{
1 Это презрительное отношение к актерам перешло в Европу. Даже Мольера, величайшего драматурга Франции, запретили хоронить на освященной земле, так как он сам играл в своих пьесах.
} 
Итак, это редкая пьеса, призванная не повеселить сограждан, а исправить их и научить добру! Это ставит нашу комедию в один ряд с аристофановскими: ибо единственный раз Плавт предстает перед нами в роли «учителя взрослых». Чему же он их учит?

Чтобы ответить на этот вопрос, мы должны рассмотреть сюжет комедии.

Некий Гегион, человек достойный и уважаемый согражданами, имел двух сыновей. Старшего похитили еще ребенком. Несчастный отец всю любовь сосредоточил на меньшем, в котором души не чаял. Но вот началась война, и его любимец попал в плен к неприятелю. Отец буквально обезумел от горя - вообще Гегион, человек больших страстей, не знающий меры ни в любви, ни в гневе, ни в горе, ни в радости. И вот он пошел на дело неслыханное: стал скупать пленных в надежде найти какого-нибудь знатного человека, которого можно было бы выменить на сына. Один из героев говорит по этому поводу: «Как я взгляну на этот дом, каждый раз плачу: ведь он ради сына взялся за бесчестный и совершенно чуждый его характеру промысел - он покупает пленных... Мне больно, что несчастный старик с горя по сыну взялся за ремесло тюремщика» (Capt., 97-100, 129-130).

Среди очередной партии пленных попадают в руки Гегиона два молодых человека. Когда их выводят на сцену в наручниках, кандалах, с железными ошейниками на шее, то вид у этих несчастных, столь юных, столь преданных друг другу, вчера еще счастливых и свободных, а ныне жалких рабов, вызывает сочувствие у самого надсмотрщика. Тронут и Гегион. Он не может глядеть на них без слез и немедленно приказывает снять с них цепи. Видя, что это образованные юноши и хорошего круга, он спешит объяснить им, зачем он взялся за мерзкое ремесло, дабы они не приняли его за профессионального работорговца.

«Я вовсе не считаю, что всякая прибыль полезна человеку, - говорит он, - многих людей прибыль запятнала. Иногда даже ущерб бывает лучше прибыли. Я ненавижу деньги: слишком многих соблазняли они на зло. Теперь послушайте внимательно, чтобы хорошо понять мои чувства. Мой сын там у вас в Элиде ${ }^{1}$ раб и пленник. Верни мне его, и я отпущу и тебя и вот его даром, и не возьму с вас ни гроша» (Capt., 325-332).

Один из пленных оказался знатным юношей, другой - его рабом. Они отлично знают, к кому попал сын Гегиона и обещают все устроить. Решено послать раба-пленника с поручением к его хозяину, отцу юноши, который может вызволить сына Гегиона. Договор заключен.

\footnotetext{
${ }^{1}$ Напоминаю, что все пьесы Плавта и Теренция развертываются в условной Греции.
} 
Гегион в восторге: через несколько дней он обнимет сына! Увы! Он и не подозревает обмана. Юноши успели сговориться, и тот, кого он отпустил - господин, а в залог у него остался раб, добровольно пожертвовавший всем для господина. Таким образом, Гегион держит в руках не залог, а тень, соломинку; может ли она заставить господина пойти на жертвы и расходы?

Имя юноши Филократ, раб зовется Тиндар. Тиндар умен и ловок, соображает он мгновенно. Ему ничего не стоит спокойными и величественными манерами обмануть нового хозяина. Но произошло непредвиденное: человек, знавший пленников дома, открыл Гегиону истину. Тиндар был разоблачен. Ему грозит неминуемая гибель. Все герои Плавта перед лицом смерти проявляют удивительную твердость. Некоторые из них бравируют, другие встречают смерть с холодным, бесчувственным спокойствием, третьи - с дерзкой удалью. Но ни один из них не трусит, не плачет и не просит пощады. Плавт менее всего склонен был идеализировать своих героев, поэтому можно заключить, что такова была вообще отличительная черта, свойственная современникам поэта. Но никто не проявляет такого величия духа и достоинства, как Тиндар.

Когда узнав, что все его надежды рухнули, Гегион в ярости бросается на обманщика и перечисляет его преступления, Тиндар спокойно отвечает (Capt., 678-749):

\section{Тиндар}

Я признаю, все было так, как ты говоришь: он обманом ушел от тебя, и все благодаря моим стараниям и хитроумию. За это ты и гневаешься на меня?

\section{Гегион}

О, за это ты заплатишь мне страшной мукой!

\section{Тиндар}

Лишь бы погибнуть не за дурное дело, а сама по себе смерть мне ничто. Если я погибну... мой подвиг будет жить и мертвому мне принесет славу. Люди будут рассказывать, как моего хозяина, которого пленником увели враги, я сделал свободным и вернул отцу и отечеству, и предпочел скорее подвергнуть опасности свою голову, чем погубить его.

\section{Гегион}

Ты пожнешь славу на берегах Ахеронта!

\section{Тиндар}

Кто погиб доблестно, тот не погиб!.. После смерти нам нечего уже бояться. Даже если я проживу до старости, все-таки жизнь - всего лишь короткий отрезок времени, в который я могу вытерпеть все, чем ты мне грозишь. Будь жив и здоров, хотя ты заслуживаешь совсем иных слов. 
Вне себя от гнева Гегион приказывает снова заковать пленника и отвести его в каменоломню. Но недолго томился он там. Филократ примчался его освободить. Он привез с собой сына Гегиона, спасенного им из рабства. Теперь Гегион не знает, как выразить свою благодарность. Он спрашивает, чем отплатить за добро Филократу. Филократ отвечает, что хочет одного - Тиндара. Но тут выясняется самое удивительное. Гегион неожиданно получает неопровержимые доказательства тому, что несчастный Тиндар - его собственный родной сын, похищенный у него в детстве! Немедленно посылают за Тиндаром. Он появляется перед зрителями бледный и измученный, ему кажется, что он действительно вернулся из царства Аида. Гегион со слезами обнимает его, просит прощения и объявляет, что он его отец. Так кончается эта замечательная пьеса.

Тема комедии - рабство. С начала до конца речь идет о рабстве в разных его формах. С первых же минут на сцене появляются люди в тяжелых кандалах и цепях. Плавт говорит, что, посмотрев его пьесу, зрители станут лучше. Каким образом? Ответ может быть только один. Они станут смотреть на рабов, как на таких же людей, что и они сами, только попавших в беду. Вся пьеса построена так, что мы должны жалеть рабов Гегиона, ремесло скупщика рабов приравнивается к ремеслу тюремщика и даже палача (Capt., 132). Вы сегодня свободны, настойчиво говорит нам Плавт, а завтра можете стать рабами. И финал пьесы - обычный в эллинистической комедии мотив «узнавания» пропавшего ребенка - принимает новый глубокий смысл. Все мы братья, словно говорит в заключение поэт. И надолго должны остаться в памяти зрителей слова Тиндара: «Судьба лепит и мнет людей, как ей заблагорассудится. Меня, который был свободен, она сделала рабом, свергнув с высоты в бездну. Меня, привыкшего повелевать, она заставила исполнять чужие приказания. Правда, если бы я нашел такого господина, каким был некогда сам, я бы мог не страшиться жестокости и несправедливости... Некогда я был свободен, как твой сын. Так же как и у него, у меня отняла свободу вражеская рука. Он служит у наших точно так же, как я служу у тебя. Но есть Бог, который видит и слышит все, что мы делаем. И он будет заботиться о твоем сыне в соответствии с тем, как ты обращаешься со мной. За добро он воздаст добром, но и за зло воздаст равной мерой. Ведь мой отец тоскует обо мне так же, как ты о своем сыне» (Capt., 304-316).

Эти слова производят впечатление даже на современного читателя. Но совсем особый смысл имели они для римлян. Ведь комедия поставлена была во время Второй Пунической войны или сразу после нее. Тысячи римлян попали в плен и томились в рабстве в разных 
частях мира. Глядя на Тиндара, зрители вспоминали своих сыновей, отцов и братьев. Его судьба должна была особенно поразить зрителей. Римляне тех лет, воспитанные в идеалах суровой доблести, не могли без волнения видеть примеры благородного самопожертвования. Цицерон вспоминает, что еще в его время зрители более всего были тронуты не несчастьями Ифигении или Ипполита, а тем, как Орест и Пилад, попав в плен, великодушно жертвовали жизнью один ради другого. Зал не мог удержаться от слез. В суровую же эпоху Плавта, когда люди буквально вырастали в военном лагере и им каждый день угрожали плен и рабство, один вид пленников должен был глубоко взволновать их. Слишком сильно отдавалось горе Гегиона, Тиндара и Филократа в их душах. Самопожертвование героев и их верность должны были восхитить римлян.

Но что замечательнее всего: все те же качества, которые более всего ценили римляне - мужество, верность, готовность пожертвовать собой, героизм, благородное стремление к славе, - все они воплощены в Тиндаре, а Тиндар этот - раб.

Мало этого. У нашей пьесы есть еще одна уникальная особенность. Чтобы комедия действительно стала школой для взрослых, она должна быть актуальна. Все Афины покорны всесильному демагогу Клеону. Афиняне отправляются в театр и в очередной пьесе Аристофана слышат безжалостную критику всех его действий. Идет Пелопоннесская. Афиняне отправляются в театр и слышат призывы кончить бессмысленную бойню и напоминание о том, что все эллины братья. И комедия говорила не только о политике. Философы обсуждают проекты коммунистического государства. А в театре зрители видят, как это государство было построено прямо в Афинах и что из этого вышло. Словом, комедия немедленно откликалась на все события, случавшиеся в обществе. Поэтому комедия должна была быть поставлена в определенный год. Ее нельзя было отложить на несколько лет. Ведь нелепо было услышать со сцены критику Клеона, когда он уже умер, или призывы к миру, когда война уже кончилась.

Совсем иным был римский театр. Как мы уже говорили, действие там разворачивалось в некой условной Греции, где ничего не менялось. Проходили годы, а зрители видели одно и то же - беспутные сыновья с помощью ловких рабов одурачивают простофиль-отцов и крадут девиц у сводника. Но наша комедия и тут представляет исключение. Она актуальна.

Во-первых, как мы уже говорили, никогда больше столько римлян не попадало в рабство. Многие современники Плавта, вероятно, поступали как Гегион. И предупреждение - как вы будете обращаться 
со своими рабами, так на чужбине обойдутся с вашими сыновьями прозвучало со сцены как грозное пророчество.

Но была и вторая причина. Как раз в это время знаменитый современник Плавта Марк Порций Катона Старший начал свою долгую и непримиримую борьбу за чистоту нравов. Своими главными врагами он считал роскошь, расточительство и греческие обычаи. Сейчас не место говорить об этой проповеди. Коснусь только одного пункта. Катон во многих отношениях был новатором и его образ действий ужаснул бы предков, о которых он столько говорил. Он, например, открыто объявил своей целью приобретение богатства. «Усердно хлопоча о преумножении своего имущества, он ... стал помещать деньги надежно и основательно; он приобретал водоемы, горячие источники, участки, пригодные для устройства валяльных мастерских, плодородные земли с пастбищами и лесами ... и все это приносило ему много денег, так что, по словам самого Катона, даже Юпитер был не в силах причинить ущерб его собственности. Занимался он и ростовщичеством, и вдобавок самым гнусным его видом... Он ссужал в долг и собственным рабам. Те покупали мальчиков, а потом, через год, как следует их выучив и вымуштровав на средства Катона, продавали... Стараясь и сыну внушить интерес к подобным занятиям, он говорил, что не мужчине, а слабой вдове приличествует уменьшать свое состояние. Еще резче высказался он, не поколебавшись назвать божественным и достойным восхищения мужем всякого, чьи счета после смерти покажут, что за свою жизнь он приобрел больше, чем получил в наследство» (Plut. Cat. mai., 21).

Для нас особый интерес представляет один способ приобретать деньги, предложенный Катоном. В своей неутомимой погоне за прибылью он занимался работорговлей, кроме того советовал продавать старых рабов, чтобы не кормить дармоедов (Plut., Cat. mai., 4). Этот совет вызывает глубокое возмущение у его биографа Плутарха. «Мне то, что он, выжав из рабов, словно из вьючного скота, все соки, к старости выгонял их вон и продавал, - мне это кажется признаком нрава слишком крутого и жестокого, не признающего никаких иных связей между людьми, кроме корыстных. А между тем, мы видим, что доброта простирается шире, чем справедливость... Человеку порядочному приличествует доставлять пропитание обессилевшим от работы коням и не только вскармливать щенков, но и печься об одряхлевших псах... Нельзя обращаться с живыми существами так же, как с сандалиями и горшками, которые выбрасывают, когда они от долгой службы прохудятся и придут в негодность, и если уж не по какой иной причине, то хотя бы в интересах человеколюбия должно обходиться 
с ними мягко и ласково. Сам я не то что одряхлевшего человека, но даже старого вола на продал бы, лишая его земли, на которой он воспитывался и привычного образа жизни, и ради ничтожного барыша, словно отправляя его в изгнание, когда он уже одинаково не нужен ни покупателю, ни продавцу» (Plut. Cat. mai., 5) ${ }^{1}$.

Итак, совет Катона казался Плутарху бездушным. Но Плутарх грек, живший к тому же через много лет после Катона. А как расценивали слова Порция его современники-римляне? На мой взгляд, ответом Катону и служит наша пьеса. В самом деле. Присмотримся к ней внимательнее и сравним ее с проповедью Катона. Катон говорит, что человек, наживший деньги, божественен, а каждая прибыль прекрасна и полезна. А у Плавта читаем: «Я вовсе не считаю, что всякая прибыль полезна человеку, многих людей прибыль запятнала. Иногда даже ущерб бывает лучше прибыли. Я ненавижу деньги: слишком многих соблазняли они на зло» (Capt., 325-332).

Катон торгует рабами, а Плавт говорит: «Как я взгляну на этот дом, каждый раз плачу: ведь он ради сына взялся за бесчестный и совершенно чуждый его характеру промысел - он покупает пленных... Мне больно, что несчастный старик с горя по сыну взялся за ремесло тюремщика» (Capt., 97-100, 129-130).

Катон говорит - продавайте старых рабов. А у Плавта читаем: «Судьба лепит и мнет людей, как ей заблагорассудится. Меня, который был свободен, она сделала рабом, свергнув с высоты в бездну... Некогда я был свободен, как твой сын. Так же, как и у него, у меня отняла свободу вражеская рука. Он служит у наших точно так же, как я служу у тебя. Но есть Бог, который видит и слышит все, что мы делаем. И он будет заботиться о твоем сыне в соответствии с тем, как ты обращаешься со мной. За добро он воздаст добром, но и за зло воздаст равной мерой. Ведь мой отец тоскует обо мне так же, как ты о своем сыне» (Capt., 304-316).

Поистине, это меткие и сильные ответы старому цензору!

Хочу обратить внимание на последнюю интереснейшую особенность нашей комедии. Плавт дает религиозное обоснование своему отношению к рабам. Бог наказывает за то зло, которое мы им причиняем. Откуда у Плавта такие взгляды? Дюмон отметил особую симпатию поэта к своим героям-рабам и объясняет это тем, что он был близок к поклонникам Диониса, тайное общество которых существовало в его время в Риме. У них было своеобразное братство верующих, и рабов, и свободных ${ }^{2}$. Ничто не противоречит этой гипотезе. В то же время проповедь Плавта можно объяснить, не прибегая к ней.

\footnotetext{
${ }^{1}$ Перевод С.П. Маркиша.

${ }^{2}$ Dumont J.C. Servus. Rome et l'esclavage sous la République. Rome, 1987. - P. 604.
} 
Во-первых, нельзя забывать, что окружение Плавта, его «рабочий коллектив», как мы видели, состоял из рабов или бывших рабов. Даже музыку к пьесам писали рабы. Это могло заставить поэта столь энергично выступить на их защиту. Во-вторых, не только новый культ Диониса, но и традиционная римская религия, как отмечал Г. Буассье, была очень благосклонна к рабам ${ }^{1}$. Она постоянно напоминала господам, что рабы - такие же люди, и призывала к гуманному к ним отношению. У них были общие праздники, и рабы в это время получали отдых. На праздник Fors Fortunae дарили подарки рабам, а в июльские ноны - рабыням (Ovid. Ars am. II, 255-258). А на Сатурналии в воспоминание о Золотом веке рабы возлежали за столом, а господа прислуживали им. Мало этого. Рабы не только молились тем же богам рядом с господами, но могли быть избраны жрецами. Во время праздника компиталий рабы должны были принимать участие в священнодействиях, «так как служение рабов было угодно Ларам» (Dionys. IV, 14). Считалось, что боги заботятся и о свободных, и о рабах.

Словом, если перед лицом закона они и бывали бесправны, перед лицом богов они были такими же людьми, как и господа. Вот почему я думаю, что голос Плавта был услышан и призыв вызвал сочувствие.

${ }^{1}$ Буассье Г. Римская религия от времен Августа до Антонинов. - М., б.г. C. 652 . 